\title{
Preventive Strategies on Pragmatic Failure in Intercultural Communication
}

\author{
Rui $\mathrm{Li}^{1, \mathrm{a}}$, Yanming $\mathrm{Li}^{2, \mathrm{~b}}$ \\ ${ }^{1}$ College of Foreign Languages, Bohai University, Jinzhou, 121013, China \\ ${ }^{2}$ School of Applied Technology, University of Science and Technology Liaoning, Anshan, 1114000, \\ China \\ aselinalr@163.com, basliyanming@163.com
}

Keywords: intercultural communication; pragmatic failure; preventive strategies; competence constitution

\begin{abstract}
With the development of the world's economic and the increasing of intercultural communication, the pragmatic issue in the intercultural communication has attracted the attention of domestic and foreign scholars. The paper based on the research results of Kim, Spitzberg, JudithMartin, ThomasNakayama and other scholars proposed the competence components on intercultural communication, and then put forward pragmatic failure preventive strategies. Specific strategies include building intercultural communication ability system, strengthen understanding of cultural differences, developing dynamic thinking skills, updating cultural teaching strategies and focusing on the subject of cultural awareness training. Results of this study provide practical implementation programs for communicators and improve the cultural ability for society, avoid the intercultural pragmatic failure resulted from cultural differences and promote the smooth progress of intercultural communication.
\end{abstract}

\section{Introduction}

Intercultural communication refers to the communication between native speakers and non-native speakers, also refers to the communication among any differences people in language and cultural background. Due to the different nation have different ecology, physical, social and religious, and therefore their language environment produced different language habits, social culture and customs, also caused the different speaking ways and habits. Thus, in communication, people always like to speak in their own way to interpret each other's words; it is possible to speak to each other to make inferences inaccurate, resulting in conflict and obstacles. Intercultural communicative competence is proposed for cultural conflict, is a kind of competence on the bases of understanding and mastering the basic knowledge of foreign cultures and communication skills to deal with the practical problems arisen in the intercultural communication.

With the advance of globalization, the communication among people from different cultural backgrounds increasingly frequent, the collision of different regional culture is more and more, this new cultural fusion attracted the attention of many linguists, become the research focus for pragmatics and applied linguistics. A variety of language skills is a necessary means of communication, certain language cultural knowledge; social background is an indispensable factor in communication. Because there are differences between the national languages and cultures, people from different countries and regions in intercultural communication process will inevitably produce errors, caused intercultural communication pragmatic failure and affect impact of communication effects. Regardless of its form or its performance reasons, the intercultural communication pragmatic failure has its own universality and complexity, and even includes some degree of uncertainty. This article is designed to help communicators enhance their perceptive and sensitivity to the target language culture, to provide practical implementation of the program for the communicators, improve the ability to the socio-cultural, avoid intercultural pragmatic failure caused by cultural differences and promote the smooth progress of intercultural communication. Meanwhile providing guidance to language teaching, in order to seek the effective language 
communication, avoid or reduce the occurrence of pragmatic failures phenomenon language for the teaching approach.

\section{Constitution on Intercultural Communicative Competence}

Kim is a distinguished scholar in the intercultural communication research field, he using social psychology; applied linguistics and sociology method combined the influencing factors of intercultural communication competence to form a new intercultural communication competence model. He believes that intercultural communication competence constituted by the cognitive, emotional competence and behavior, three factors interrelated and influence each other, indivisible; Spitzberg think intercultural communication competence constituted by the knowledge, motivation, skills, constitute the three factors, the three mutual effect of interdependence. Intercultural communication competence requires adequate intercultural knowledge, positive motivation and effective communication skills, three factors should also have, any of these factors can not constitute a intercultural communication competence alone; JudithMartin and ThomasNakayama prepared "intercultural communication in the context", in which proposes a new intercultural communication competence model, including knowledge factors, emotional factors, mental activity characteristics and situational characteristics of the four elements. This paper takes the front four scholars view as the foundation, and combined with the research results of basis people, the constitution of intercultural communicative competence is shown in Fig. 1.。

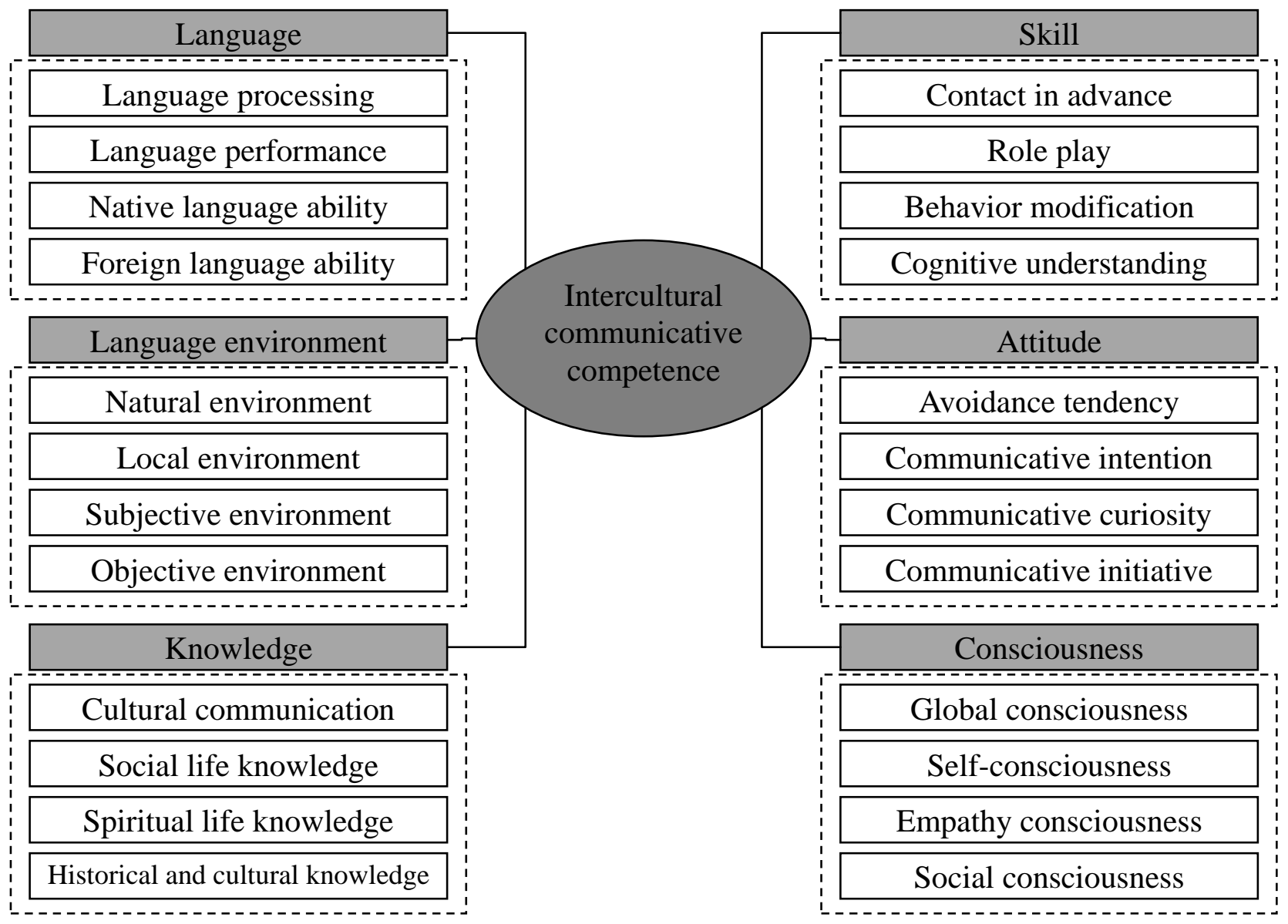

Fig. 1. Constitution on intercultural communicative competence

Intercultural communication competence constitution shown in Fig. 1 briefly described as follows [1-3]:

(1) Language. Language is mankind's most important communication tool for people to communicate in a variety of expressions. Language is the carrier of culture; it is by means of language preservation and transfers the achievements of human civilization. Not only to learn the 
language as much as possible knowledge of the voice, vocabulary, grammar, etc., as much as possible to grasp the pronunciation and meaning of words.

(2) Context. It refers to the condition and status to speak. Natural language environment refers to native speakers of the language living environment; local language learner environment is part of life or learn the language environment; subjective context refers to communication motivation, communication competence and behavior personnel related communication; objective context is the other factors beyond communicators.

(3) Knowledge. Knowledge includes broad cultural knowledge and narrow cultural knowledge. Broad cultural knowledge explains intercultural communication from a macro phenomenon; does general guidance to intercultural communication behavior for communicators. Narrow cultural knowledge is a certain culture of knowledge and common sense, such as the culture is different from other cultural characteristics, as well as its mainstream cultural patterns and benefits and so on.

(4) Skills. The skill is decent, effective communication behavior manifested in intercultural communication. Communicators have only the necessary intercultural communicative knowledge, hold positive communicative motivation is not enough to complete the communication task, must also use certain skills. For example, the ability to conduct work, transformation strains, eclectic take on different social situations in different ways.

(5) Attitude. Attitude is some stable individual psychological tendency held on a specific object. This tendency implies an individual's subjective evaluation and behavioral tendency. Intercultural communication competence refers to that communicators hold the attitude and communication motivation to other cultures and their own culture, curiosity, tolerance and acceptance and so on about other cultures.

(6) Awareness. Mainly refers to the self as well as an associated person or affairs knowledge, including exploration, experiment and experience, self-reflection, self-expression can be demonstrated to others. Consciousness has irreversible characteristics, can not return to the original state of unconsciousness, can improve cognitive, emotional and behavioral skills, and therefore should focus on training content intercultural communication awareness.

\section{Preventive Strategies on Pragmatic Failure}

The strategy refers to plan or strategy; it is program set to achieve objectives. Solving the core problem of intercultural communication pragmatic is how training and improve intercultural communication competence, which is to reduce or prevent pragmatic failure to form an effective Intercultural Communication mode of basic conditions. Intercultural communication language will need to study many aspects Strategies to prevent mistakes can be effective, it is a complex systematic work. The preventive strategy on pragmatic failure in intercultural communication is shown in Fig. 2. For each strategy described as follows [4-9]:

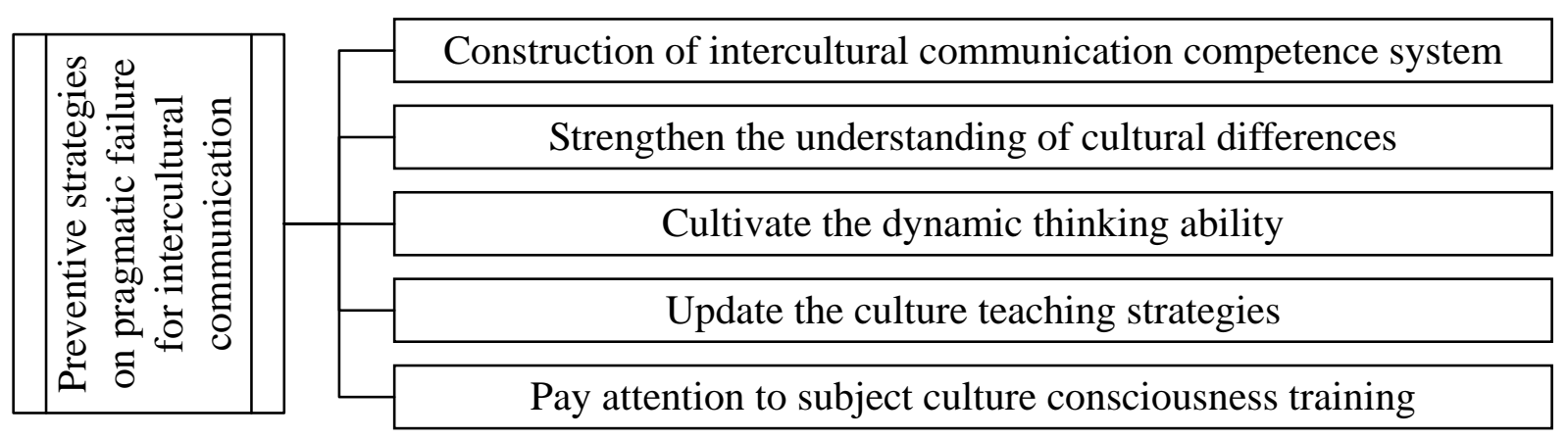

Fig. 2. Preventive strategies on pragmatic failure for intercultural communication

(1) Building intercultural communication ability system. Intercultural communication competence system consists of a basic communication capability of the system, the emotional relationship capacity of the system, the ability to plot strategy systems and communicative ability of the system components. Basic communicative ability of the system, mainly by the individual 
communication to achieve effective communication that should be mastered verbal and non-verbal behavior ability, cultural competence, ability and cognitive interaction composition; emotional relationship capacity of the system, emotional competence mainly refers to empathy, Empathy is a not only share feelings of others, empathy for the situation of others, but also an objective understanding, the ability to analyze feelings of others. When the relationship between communicators capacity increased, intercultural communication ability also increased accordingly. Namely the ability to establish the relationship between communicators, maintain some kind of relationship communication, and communication in this relationship by the two sides to meet and adapt to each other and the ability to achieve effective communication; the ability of the system plot, plot by the ability of the system to follow the logic of meaning and behavior of the general plot capacity and beyond and to change the rules to follow their own custom super plot constituted ability; communicative strategies capacity of the system, in the communication process, because the language or pragmatic competence flawed reach the communication purpose or cause communication errors when used in a series remediation strategies.

(2) Strengthen understanding of cultural differences. Mutual understanding differences between different cultural backgrounds will on the people of culture and harmony bring great difficulties to make people worry and depression, or have a significant sense of loss. Does exist among different ethnic cultures very different nature, and this difference is rooted in people's minds, it is difficult to be changed. Cultural differences are caused by different historical traditions and social development of our countries arising from the performance in all aspects of society and culture. People are always in a certain language and cultural environment in growth, affected the language of a particular culture, people from different language and cultural backgrounds to communicate when, inevitably encounter obstacles. Many take for granted the phenomenon, for exotic cultures, it may be strange, even difficult to understand, it is because a lack of understanding of the language and cultural differences. Therefore, strengthening the contrast between different languages, enhance mutual communication is an important way to understand each other, but also an effective way to improve intercultural communicative competence. In the process of contrasting need to exclude ethnocentrism and prejudice and to recognize comparison purposes that only to promote full understanding among different cultures, thereby reducing the pragmatic failure, to better promote communication.

(3) Developing dynamic thinking skills. Dynamic thinking refers to a movement, adjustability, and constantly thinking of preferred activities. According to changing environmental conditions to change thinking process, the direction of thinking of things to adjust, control, so as to achieve the goal of thinking optimization. From the perspective of cognitive context, the cross-cultural communication not only to recognize the language of communication is not a simple sentence in isolation from the environment, understanding of language is not limited to the internal structure of the language and the literal sense, but also time to realize that communication process is a process of reasoning required, is the need to combine the elements of judgment to make the process of selection. That is, the communication as a cognitive activity is not a simple linear process of meaning superimposed, but the premise of cognitive context "matching, restructuring, conversion" the iterative process. Cognitive context comparable to a complex network involving their language skills, cultural background, education, experience, living environment, way of thinking and so on, any information in this network system may affect the selection and judgment to the significance of language for communicators. This requires communicators to have the ability to dynamically thinking, while receiving the information, according to the background, meaning the field scene of the relevant information continuously adjust and optimize, to make a final judgment.

(4) Updating cultural teaching strategies. With the deepening of education for the rich language, language teaching and cultural connotation of understanding not only to impart knowledge of the language, but also include cultural knowledge, training students to use a foreign language intercultural communication. Thus, intercultural communication and foreign language teaching are inseparable, intercultural education is a necessary part of foreign language teaching. Foreign language teaching to update cultural teaching strategies, mainly in the following ways: on the 
cultural differences between the native language and the target language to compare; full use of a variety of teaching methods pictures, video, network and create ambience of foreign cultures; to guide students to read foreign literature, perspective of cultural nature, cultural identity and the purpose of the author's mental state such as the national language; attention disseminate foreign cultural background and customs, so that students can get more cultural information; the creation of a certain culture the teaching of cultural knowledge scenarios, so that students experience the exotic culture; offers a variety of activities for students, personal experience of foreigners express thoughts and feelings and behavior. In short, the foreign language teaching process, to mobilize the enthusiasm of the students, the language of teaching and understanding of culture combine active scene teaching, to cultivate students' ability to use language in the context of the right form of communication.

(5) Focusing on the subject of cultural awareness training. Intercultural communication in communicative language and cultural background differences between people, cultural differences in communication, only understand a culture, do not have the ability to intercultural dialogue, it is difficult to achieve a real sense of intercultural communication and the purpose of communication. Cross-cultural communication requires two cultures have to understand, especially for their own national cultural understanding. Only with their cultures, cultural awareness body, to maintain their national identity, cross-cultural perspective to understand foreign cultures into intercultural dialogue state. First, from the appearance of foreign cultures to understand the level of depth to the rational level, the culture of high-grade humanities messenger of the new intercultural communication; secondly, to develop students' cultural consciousness, cultural identity and enhance national identity and self-confidence. Do not blindly follow the worship of foreign cultures, the loss of their national cultural identity; again, avoid intercultural communication dislocation, missing by their culture, no cultural awareness body, in cross-cultural communication and cultural dislocation often occurs; and finally, attach importance to training students of foreign language skills unique phenomenon, not only a deep understanding of the local culture to make the learners, but also to master a foreign language to express local culture.

\section{Conclusion}

With the rapid development of economic globalization, the communication between China and other countries have become increasingly frequent, if you do not understand the cultural context, thinking ways, values and other differences about communicators, it will result in a large number of pragmatic failure, the communicator will produce embarrassment, misunderstandings and other scenes, is bound to affect the communication. Intercultural communication can help communicators with different cultural backgrounds through communication to better understand and know each other, make themselves aware of the exchange deems appropriate and suitable language and discourse might be considered in a different cultural environment background inappropriate verbal behavior, and be able to find timely communication barriers and communication difficulties, the know how to take certain remedial measures to adjust their speech codes of conduct, in order to avoid communication conflicts, achieve the purpose of smooth communication. Research method of this paper is proposed for the current intercultural communication ability, the actual time is to analyze specific issues, in order to make the strategies more in line with the actual communication situation.

\section{Acknowledgement}

This work is supported by social science fund project of Liaoning province (L14BYY014): Research on Pragmatic Failure and Its Strategy for Intercultural Communication.

\section{References}

[1] L. Gao, F. Wang, "A tentative approach to intercultural communicative competence," Journal of 
Northwest University (Philosophy and Social Sciences Edition), vol. 37, no. 3, pp. 116-119, 2007.

[2] L. Wu, "Pragmatic failure and preventive strategies in cross cultural communication," Educational theory and Practice, vol. 34, no. 24, pp. 46-47, 2014.

[3] Baidu library, "Intercultural communicative competence," http://wenku.baidu.com/link?url=pr-uORfEpQMV8IXfk5OjvMHNZBLPFOJ9xpNGW8SL231 P3xXVtwOsyd1Rxmz29N6wICHgVFpixxW69Mj5VB1s11kUF00FLOs-5eE9RxLBosy, 2015-8-21.

[4] X. R. Chen, M. Li, "Under the background of English as an international language pragmatic failure data processing," Foreign language and foreign language teaching, vol. 37, no. 2, pp. 7-12, 2015.

[5] W. Yan, X. L. Zhang, "Pragmatic Failure in Cross - Cultural Communication and the Avoidance Strategy," Journal of Shanxi Agricultural University(Social Science Edition), vol. 13, no. 6, pp. 601-605, 2014.

[6] Y. Yan, "Forms and Counter - measures of Pragmatic Failure Experienced by Second Language Learners in Intercultural Communication," Journal of Lianyungang Teachers College, vol. 26, no. 4, pp. 27-29, 2009.

[7] L. Wu, "Research on analysis and countermeasures for pragmatic failure in cross cultural communication," Overseas English, vol. 16, no. 5, pp. 218-219, 2015.

[8] H. Q. Zhang, "On cultural subject consciousness in cross cultural communication," Journal of Beijing International Studies University, vol. 35, no. 6, pp. 87, 2013.

[9] H. Q. Zhu, "Analysis and countermeasures on foreign students Chinese pragmatic failure," Journal of Hubei University of Economics (Humanities and Social Sciences), vol. 12, no. 8, pp. 118-120, 2015. 